\title{
PENGETAHUAN TIM REAKSI CEPAT TENTANG BANTUAN HIDUP DASAR
}

\author{
${ }^{1}$ Ulfah Nasti Wiliastuti, ${ }^{2}$ Anastasia Anna, ${ }^{3}$ Ristina Mirwanti \\ Fakultas Keperawatan, Universitas Padjadjaran, Bandung, Jawa Barat \\ E-mail: ristina.mirwanti@unpad.ac.id
}

\begin{abstract}
Abstrak
Cardiac arrest termasuk kejadian kegawatdaruratan yang membutuhkan bantuan hidup dasar dengan resusitasi jantung paru. Upaya pertolongan bantuan hidup dasar yang terlambat diberikan dapat berdampak kematian pada pasien. Tim reaksi cepat sebagai tenaga kesehatan yang dibentuk khusus untuk menangani pasien kegawatdaruratan dituntut mampu memberikan pertolongan pada pasien gawat darurat dengan cepat dan tepat. Tim reaksi cepat membutuhkan pengetahuan dalam melakukan tindakan bantuan hidup dasar. Tujuan penelitian ini untuk mengidentifikasi pengetahuan Tim Reaksi Cepat tentang Bantuan Hidup Dasar. Penelitian ini menggunakan metode deskriptif kuantitatif pada 37 anggota tim reaksi cepat yang dipilih menggunakan total sampling. Instrumen penelitian menggunakan kuesioner pengetahuan yang disusun dan dikembangkan peneliti. Hasil penelitian menunjukkan bahwa pengetahuan sebagian besar dalam kategori kurang yaitu sebanyak 36 responden (97,3\%) dan satu responden $(2,7 \%)$ memiliki pengetahuan baik. Responden dengan katergori pengetahuan yang kurang memiliki kategori kurang di semua indikator seperti, pada pengetahuan konsep dasar, pengkajian respon dalam BHD, resusitasi paru dalam BHD, resusitasi jantung dalam BHD, dan AED dalam BHD. Perlu adanya peningkatan pengetahuan tentang bantuan hidup dasar dengan mengadakan pelatihan, evaluasi serta pembaharuan standar prosedur operasional BHD.
\end{abstract}

Kata kunci: Bantuan hidup dasar, pengetahuan, Tim Reaksi Cepat

\begin{abstract}
Cardiac arrest is one of emergency events that requiring basic life support (BLS) which is cardiopulmonary resuscitation. Rescue efforts that given late have an impact on the patient's death. Code blue team which is specially formed from health workers with the purpose to handle emergency patients is required to provide emergency care with quick and accurate. Code blue team needs knowledge in performing basic life support. The purpose of this study was to identify knowledge of Code Blue Team about Basic Life Support. This study used quantitative descriptive method on 37 members of code blue team that have been selected by using total sampling. The research instrument used knowledge questionnaire that has been compiled and developed by researcher based on basic life support literature and has been passed validity content. The results showed that knowledge in mostly in the less category, as many as 36 respondents (97.3\%) and only 1 respondent (2.7\%) had good knowledge. Respondents who has less knowledge had less category on every indicator such as basic concept of knowledge, assessment of response in CPR, lung resuscitation in $C P R$, cardiac resuscitation in $C P R$, and AED in CPR. Improving knowledge of basic life support is needed by conducting training, evaluation, and updating the standard of procedure operational on CPR.
\end{abstract}

Keywords: Basic Life Support, Knowledge, Code Blue Team

\section{PENDAHULUAN}

Kematian jantung mendadak atau cardiac arrest adalah berhentinya fungsi jantung secara tiba - tiba pada seseorang yang telah atau belum diketahui menderita penyakit jantung (American Heart Association, 2010). Menurut survei Centers for Disease Control and Prevention (CDC) di United State didapatkan kasus henti jantung 31.689 selama lima tahun (2005-2010) dan 33,3\% mendapatkan bantuan resusitasi jantung paru (RJP) dari saksi yang sudah terlatih serta $3,7 \%$ menggunakan automated external defibrilator atau AED (Bryan et al, 2011). Prevalensi henti jantung di Indonesia setiap tahunnya belum didapatkan data yang jelas akan tetapi prevalensi terjadinya penyakit 
jantung di Indonesia sebanyak 7,2\% (BPPK, 2008). Menurut data salah satu rumah sakit di Jawa Barat, (Januari-Mei 2015) terdapat 57 kasus pasien meninggal akibat cardiac arrest.

Cardiac Arrest atau henti jantung menjadi kasus kegawatdaruratan yang harus mendapatkan penanganan yang tepat dan segera dari petugas medis atau masyarakat umum yang sudah terlatih. Kematian otak dan kematian permanen terjadi dalam jangka waktu 8 sampai 10 menit setelah seseorang mengalami cardiac arrest (Pusponegoro A, 2010). Salah satu penanganan yang harus diberikan pada cardiac arrest adalah bantuan hidup dasar dengan RJP. Penanganan yang terlambat atau tidak tepat pada pasien dengan henti jantung dapat berakibat fatal, yaitu kematian dalam hitungan menit (Vaillancourt, Christian, Stiell, dan Ian, 2004).

Kesempatan pasien untuk bisa bertahan hidup berkurang 7 sampai 10 persen pada tiap menit yang berjalan tanpa cardiopulmonary resusitation dan defibrilasi (American Heart Association, 2010). Berdasarkan hasil penelitian dari American Heart Association pada bulan Juni 1999 didapatkan data bahwa $64 \%$ pasien dengan cardiac arrest yang mendapatkan penanganan segera dapat bertahan hidup tanpa kerusakan otak.

Cardiac arrest merupakan insiden kegawatdaruratan yang membutuhkan bantuan hidup dasar dengan resusitasi jantung paru. Basic Life Support (BLS) atau Bantuan Hidup Dasar merupakan tindakan pertolongan pertama yang dilakukan pada korban dengan henti napas dan henti jantung. Bantuan Hidup Dasar terdiri atas serangkaian tindakan pertolongan pertama memberikan napas buatan dan tekanan jantung luar pada pasien yang mengalami henti napas dan henti jantung (American Heart Association,
2010). BHD merupakan salah satu upaya yang harus segera dilakukan oleh seseorang apabila menemukan korban yang membutuhkan oleh karena itu, setiap tenaga kesehatan wajib menguasai BHD (Keenan, Lmacraft \& Joubert, 2009).

RJP merupakan bagian dari bantuan hidup dasar yang membantu jantung dapat kembali berfungsi memompa dan memperbaiki sirkulasi darah dalam tubuh. Bantuan hidup dasar dapat dilakukan oleh siapapun terutama oleh TRC sesegera mungkin pada saat awal terjadinya henti jantung untuk meningkatkan angka kelangsungan hidup (Suharsono dan ningsih, 2009).

Inti dari penanganan cardiac arrest adalah kemampuan seseorang untuk dapat mendeteksi dan beraksi secara cepat dan benar untuk sesegera mungkin mengembalikan denyut jantung ke dalam kondisi normal sehinga dapat mencegah terjadinya kematian otak dan kematian permanen. Selain itu, kunci penanganan kondisi kegawatdaruratan adalah harus adanya kesinambungan dari orang yang pertama kali menemukan harus memiliki pengetahuan tentang BHD, pelayanan ambulans, UGD, ICU sampai pada ruang perawatan) harus satu bahasa dalam memandang keadaan kegawatdaruratan (Pusponegoro A, 2010).

Tim Reaksi Cepat (TRC) sebagai tenaga kesehatan yang dibentuk khusus untuk menangani pasien kegawatdaruratan dituntut mampu memberikan pertolongan pada pasien gawat darurat dengan cepat dan tepat. TRC adalah tim yang bertugas memberikan pertolongan segera pada pasien dengan kegawatdaruratan sebelum dan saat henti napas henti jantung. TRC merupakan bagian dari Code Blue System, yaitu sebuah kode isyarat internasional yang digunakan di dalam rumah sakit yang menandakan adanya 
seorang pasien yang sedang mengalami serangan jantung atau mengalami situasi gagal napas akut dan situasi gawat darurat lalinnya yang menyangkut dengan nyawa pasien.

Peningkatan kebutuhan pelayanan pertolongan gawat darurat, menuntut tim reaksi cepat memiliki pengetahuan yang cukup untuk melakukan tindakan dalam memberikan pelayanan kesehatan (Svensson \& Fridlund, 2008). Proses pengkajian yang dilakukan secara sistematis yang dimulai dari memeriksa kesadaran, melakukan RJP dan tindakan defibrilasi harus dilakukan secara cepat (Herlitz, 2006). Maka dari itu pendidikan dan pelatihan tentang BHD penting diikuti oleh anggota tim reaksi cepat sebagai pemberi pertolongan kegawatdaruratan.

Hasil penelitian yang dilakukan Alhidayat (2013) menunjukkan bahwa terdapat hubungan yang signifikan antara tingkat pengetahuan perawat Instalansi Gawat Darurat tentang pengkajian primer terhadap tindakan life support di Rumah Sakit Pelamonia Makassar. Dari penelitian ini didapatkan bahwa perawat dengan tingkat pengetahuan tentang pengkajian primer yang tinggi sangat berpengaruh terhadap pelaksanaan tindakan life support yang baik pula.

Penelitian yang dilakukan Dahlan (2014) mengatakan bahwa sebelum diberi pendidikan kesehatan tentang BHD yang terbanyak dalam kategori pengetahuan yang buruk, sedangkan tingkat pengetahuan tenaga kesehatan sesudah diberikan pendidikan kesehatan tentang BHD yang tebanyak dalam kategori pengetahuan baik. Hasil dari penelitian ini menunjukkan bahwa pentingnya suatu pendidikan kesehatan terhadap tingkat pengetahuan kesehatan.

\section{METODE PENELITIAN}

Penelitian ini menggunakan metode deskriptif kuantitatif dengan pendekatan cross sectional. Populasi dalam penelitian ini adalah tim reaksi cepat di rumah sakit umum tingkat kabupaten di Jawa Barat yang berjumlah 37 orang. Peneliti menggunakan metode total sampling. Pengetahuan diukur dengan menggunakan kuesioner pengetahuan tim reaksi cepat tentang BHD yang berbentuk pilihan tunggal dengan jumlah dua pertanyaan dan di beri skor "1" apabila menjawab benar dan skor "0" apabila jawaban salah. Pengetahuan dikategorikan kurang apabila mampu menjawab benar $\leq 75 \%$, yaitu skor $\leq 15$ dan pengetahuan dikategorikan baik apabila responden mampu menjawab benar $>75 \%$, yaitu skor $>15$. Penelitian ini telah melalui ethical clearance dari Komite Etik Penelitian Kesehatan FK UNPAD. Responden dalam penelitian ini dilindungi hak - haknya. Penelitian menjelaskan tujuan penelitian dan responden diberikan hak untuk bersedia atau menolak mengikuti penelitian. Responden diperlakukan secara adil dan informasi terkait penelitian ini dirahasiakan.

\section{HASIL PENELITIAN}

Tabel 1.

Distribusi Frekuensi Karakteristik Responden (N=37)

\begin{tabular}{clcc}
\hline No. & Karakteristik & $\begin{array}{c}\text { Frekuensi } \\
(\mathbf{f})\end{array}$ & $\begin{array}{c}\text { Persentase } \\
(\mathbf{\%})\end{array}$ \\
\hline $\mathbf{1}$ & Ruangan & & \\
& Rawat Inap & 15 & 40,5 \\
& IGD & 19 & 51,4 \\
& ICU & 3 & 8,1 \\
$\mathbf{2}$ & Jenis Kelamin & & \\
& Perempuan & 19 & 51,4 \\
& Laki-laki & 18 & 48,6 \\
$\mathbf{3}$ & Usia & & \\
& Dewasa Awal & 13 & 35,1 \\
$\mathbf{4}$ & Dewasa Akhir & 24 & 64,9 \\
& Pend Terakhir & & \\
& D3 & 32 & 86,5
\end{tabular}


S1

5

13,5

5 Lama Bekerja

$\begin{array}{lll}\text { Lama Bekerja 5- } & 22 & 59,5 \\ \text { Lama Bekerja > } & 15 & 40,5\end{array}$

6 Sumber

$\begin{array}{lcc}\text { informasi } & 19 & 32,2 \\ \text { Seminar/worksho } & 34 & 57,6 \\ \text { Media sosial } & 6 & 10,2\end{array}$

Tabel 1 menunjukkan $51,4 \%$ responden berasal dari ruang IGD, dan $51,4 \%$ juga berjenis kelamin perempuan. Mayoritas responden merupaka dewasa akhir $(64,9 \%)$ dengan pendidikan terakhir D3 keperawatan $(86,5 \%)$. Mayoritas responden memiliki pengalaman lama bekerja $5-10$ tahun $(59,5 \%)$ dan sebagian besar pernah mendapatkan informasi mengenai BHD dari seminar dan workshop $(57,6 \%)$.

Tabel 2.

Gambaran Pengetahuan Tim Reaksi Cepat $(n=37)$

\begin{tabular}{lcc}
\hline Pengetahuan & Frekuensi (f) & $\begin{array}{c}\text { Persentase } \\
(\mathbf{\%})\end{array}$ \\
\hline Baik & 1 & 2,7 \\
Kurang & 36 & 97,3 \\
\hline
\end{tabular}

Tabel 2 menunjukkan bahwa hampir keseluruhan tim reaksi cepat memiliki pengetahuan yang kurang terkait BHD.

Tabel 3.

Distribusi Frekuensi Indikator Pengetahuan Tim Reaksi Cepat

\begin{tabular}{lcc}
\hline \multicolumn{1}{c}{ Indikator } & $\begin{array}{c}\text { Frekuensi } \\
(\mathbf{f})\end{array}$ & $\begin{array}{c}\text { Persentase } \\
(\mathbf{\%})\end{array}$ \\
\hline$\quad$ Konsep dasar & & \\
Baik & 0 & 0 \\
Kurang & 37 & 100 \\
$\quad$ Pengkajian respon & & \\
Baik & 14 & 37,8 \\
Kurang & 23 & 62,2 \\
$\quad$ Resusitasi paru & & \\
Baik & 2 & 5,4 \\
Kurang & 35 & 94,6 \\
$\quad$ Resusitasi jantung & & \\
Baik & 2 & 5,4 \\
Kurang & 35 & 94,6 \\
$\quad$ AED dalam BHD & & \\
Baik & 2 & 5,4 \\
Kurang & 35 & 94,6 \\
\hline
\end{tabular}

Berdasarkan tabel 3, tampak seluruh responden memiliki pengetahuan yang kurang terkait konsep dasar, tetapi beberapa memiliki pengetahuan yang baik dalam hal pengkajian respons $(37,8 \%)$. Sebagian besar responden memiliki pengetahuan yang kurang terkait resusitasi jantung, paru, dan penggunaan AED $(94,65)$.

\section{PEMBAHASAN}

Pengetahuan tentang BHD sangat diperlukan oleh tim reaksi cepat. Pengetahuan BHD akan mempengaruhi perilaku dalam pemberian pertama pada pasien yang perlu diberikan BHD. Pengetahuan tentang BHD akan meningkatkan pengetahuan individu tentang mengidentifikasi tanda-tanda pasien yang harus diberikan BHD, cara-cara melakukan tahapan BHD, dan juga mengetahui tandatanda pasien yang telah dalam keadaan pulih atau tidak terselamatkan. Pengetahuan tentang BHD ini dapat mengurangi angka kematian.

Tingkat pengetahuan responden tentang BHD berdasarkan hasil penelitian ini didapatkan hasil bahwa dari 37 responden, sebagian besar responden yakni berjumlah 36 orang $(97,3 \%)$ memiliki pengetahuan kurang berkaitan dengan pengetahuan bantuan hidup dasar. Tinggi rendahnya pengetahuan seseorang dipengaruhi oleh beberapa faktor diantaranya usia, informasi, pendidikan dan pengalaman (Notoatmodjo, 2013).

Lebih dari setengah responden pada penelitian ini berada pada kategori usia dewasa akhir (34-45 tahun), yakni berjumlah 24 orang (64,9\%). Menurut Dariyo (2003) yang mengatakan bahwa pada usia dewasa awal individu mampu memecahkan masalah yang kompleks dengan kapasitas berpikir abstrak, logis, dan rasional. Hal ini sejalan dengan teori Fischer, Yan, \& 
Stewart (2003) yang mengatakan bahwa pada usia mulai dari dua puluh tahun terjadi perubahan kognitif yang sangat luas. Pada dewasa awal tersebut perkembangan kognitif menjadi lebih kaya, kompleks, dan dinamis, serta individu akan lebih banyak berperan bersama- sama dengan individu lainnya dalam berbagai konteks untuk menghasilkan variasi yang sistematis dan dinamis sedangkan teori Notoatmodjo (2003) yang menegaskan bahwa semakin bertambahnya usia maka akan semakin berkembang pula daya tangkap dan pola pikir individu, sehingga pengetahuan yang diperoleh semakin baik. Hal tersebut menunjukkan bahwa secara fisik, psikologis, mental dan kognitif responden telah berkembang, siap dan matang untuk menerima informasi. Hasil penelitian tidak sejalan dengan teori yang dikatakan oleh Notoatmodjo (2003) karena selain dari faktor usia pengetahuan dipengaruhi oleh faktor lain, yaitu faktor sumber informasi yang didapat.

Hasil penelitian ini, mayoritas responden berada pada usia dewasa akhir. Menurut hasil penelitian Lumangkun, Kumaat dan Rompas (2014) tentang hubungan karakteristik polisi lalu lintas dengan tingkat pengetahuan BHD bahwa tidak ada hubungan antara umur polisi dengan tingkat pengetahuan BHD. Penelitian tersebut menjelaskan bahwa bertambahnya umur seseorang dapat berpengaruh pada pertambahan pengetahuan yang diperolehnya. Pada penelitian ini, mayoritas responden berada pada usia dewasa akhir akan tetapi memiliki pengetahuan yang kurang terkait BHD. Pada umur-umur tertentu atau menjelang usia lanjut kemampuan penerimaan atau mengingat suatu pengetahuan juga dapat berkurang. Selain dari faktor usia pengetahuan dipengaruhi oleh faktor lain, yaitu faktor sumber informasi yang didapat.
Dari data di atas menunjukkan bahwa lebih dari setengah responden $(57,6 \%)$ pada penelitian ini memiliki sumber informasi dari seminar/workshop/pelatihan. Responden mengikuti pelatihan yang diadakan oleh pihak rumah sakit bekerja sama dengan provider pelatihan dan dilaksanakan dalam satu hari dengan pemantauan selama setahun evaluasi per tiga bulan sekali.

Menurut Notoatmodjo (2003) informasi yang diperoleh individu dapat mempengaruhi seseorang karena informasi memiliki pengaruh pada diri individu yang selanjutnya mengakibatkan perubahan atau peningkatan pengetahuan, sehingga informasi mengenai bantuan hidup dasar harus ditingkatkan, karena semakin banyak informasi yang diterima makan akan semakin banyak pula pengetahuan yang didapat. Informasi mengenai bantuan hidup dasar sudah didapat oleh tim reaksi cepat, namun informasi tersebut diterima hampir tiga bulan yang lalu. Hasil penelitian Partiprajak dan Thongpo (2016) mengungkapkan bahwa pelatihan resusitasi jantung paru memiliki efek langsung yang signifikan pada pengetahuan, self-efficacy dan keterampilan kompresi dada, namun pengetahuan dan self-efficacy menurun secara signifikan setelah tiga bulan pasca-pelatihan. Hal ini menunjukkan bahwa pengetahuan Tim reaksi cepat cenderung mengalami penurunan sehingga pengulangan dan evaluasi pelatihan dilakukan secara berkala.

Hasil penelitian Samar Toubasi, R. Alosta, Darawa dan Demeh (2015) mengungkapkan bahwa program pelatihan tentang bantuan hidup dasar memiliki efek yang signifikan pada pengetahuan. Data penelitian tersebut menunjukkan peningkatan yang signifikan dalam nilai post-test dibandingkan dengan nilai pre- test. Program pelatihan bantuan hidup dasar meningkatkan pengetahuan dan 
keterampilan perawat di rumah sakit Yordania. Hal ini tidak sejalan dengan hasil penelitian, dalam penelitian ini menunjukkan bahwa pengetahuan tim reaksi cepat cenderung mengalami penurunan walaupun sudah dilakukan seminar dan pelatihan, hal ini terjadi karena setiap orang memiliki keterbatasn dalam penyimpanan memori. Penelitian yang dilakukan oleh Anderson et al (2011) di Kanada didapatkan bahwa pengetahuan dan keterampilan memburuk dengan cepat dalam sembilan puluh hari pertama, sebaiknya pengetahuan dan keterampilan pertolongan pertama dievaluasi menggunakan metode teratur "refreshing" yang dapat dilakukan pada frekuensi tinggi, seperti setiap sembilan puluh hari (Anderson, Gaetz, \& Masse, 2011). Metode pelatihan yang digunakan juga harus efektif sehingga pengetahuan dapat tersalurkan dengan baik. Upaya pelatihan tersebut dapat diberikan oleh pihak rumah sakit.

Selain faktor usia dan informasi yang didapat, faktor lain yang mempengaruhi pengetahuan ialah pengalaman. Pengetahuan didapatkan dengan mengumpulkan informasi yang didapatkan pada kegiatan sebelumnya (Notoatmodjo, 2003). Lama bekerja di rumah sakit akan memberikan pengalaman bagi perawat dalam memberikan penanganan bantuan hidup dasar. Pengalaman merupakan hasil dari proses mendapatkan pengetahuan atau kemampuan melalui melihat merasakan dan melakukan sesuatu (Alavi, et al., 2012).

Pada penelitian ini lebih dari setengah responden dengan lama bekerja 5- 10 tahun sebanyak 22 orang (59,5\%). Pengalaman melihat tindakan BHD dan pengalaman melakukan RJP merupakan salah satu sumber pengetahuan responden. Hal ini didukung oleh penelitian Passali, et al., (2011) yang berjudul evaluasi pengetahuan dokter dan perawat mengenai BLS dan
ACLS pada 82 perawat dan 134 dokter, hasil penelitian menunjukkan bahwa perawat dan dokter yang memiliki pengalaman memberikan resusitasi jantung paru pada pasien henti nafas dan jantung langsung dan berada pada lingkungan high risk cardiac arrest memiliki pengetahuan yang lebih baik dibandingkan dengan perawat dan dokter yang tidak berada pada lingkungan high risk cardiac arrest.

Hasil penelitian ini menunjukkan bahwa responden dengan pengetahuan kurang dipengaruhi oleh faktor pengalaman lama bekerja. Setelah dilakukan wawancara terhadap tim reaksi cepat didapatkan informasi tentang ketersediaan AED yang terbatas, dalam penelitian ini responden sudah memiliki pengalaman yang cukup tetapi pengetahuan responden dalam kategori kurang hal ini dapat disebabkan oleh keterbatasan kesediaan AED yang mendukung pemberian bantuan hidup dasar kepada pasien.

Selain itu, tingkat pendidikan juga termasuk ke dalam faktor yang memengaruhi pengetahuan. Pada penelitian ini sebagian besar responden berstatus pendidikan terakhir pada lulusan D3 sebanyak 32 orang $(86,5 \%)$ dan sisanya dengan pendidikan terakhir S1 sebanyak lima orang $(13,5 \%)$ dengan pengetahuan baik satu orang berstatus pendidikan terakhir pada lulusan D3.

Menurut Grossman (1999), pendidikan merupakan salah satu kebutuhan dasar manusia yang diperlukan untuk pengembangan diri. Semakin tinggi tingkat pendidikan, semakin mudah mereka menerima serta mengembangkan pengetahuan dan teknologi, sehingga akan meningkatkan produktivitas. Hal ini bertolak belakang dengan hasil penelitian Faridah (2009) mengatakan bahwa sebagian besar 
tingkat pendidikan terakhir responden adalah D3 keperawatan $(86,36 \%)$ sedangkan sisanya dengan responden yang mempunyai tingkat pendidikan terakhir S1 keperawatan $(4,55 \%)$, dengan pengetahuan perawat tentang BHD baik. Ini mencerminkan bahwa masih sedikitnya tenaga perawat yang mempunyai dasar pendidikan S1. Berdasarkan teori dan penelitian di atas maka secara teoritis hasil penelitian ini sesuai dengan pendapat Grossman (1999) yang mengatakan semakin tinggi tingkat pendidikan, semakin mudah mereka menerima serta mengembangkan pengetahuan dan teknologi, sehingga akan meningkatkan produktivitas, karena tingkat pendidikan tim reaksi cepat yang memiliki tingkat pendidikan terakhir D3 dan memiliki pengetahuan kurang.

Pendidikan atau penyuluhan adalah upaya agar individu, kelompok dan masyarakat, berperilaku atau mengadopsi perilaku kesehatan dengan cara persuasi, bujukan himbawan ajakan, memberi informasi, memberikan kesadaran, dan sebagainya. Pendidikan nonformal tentang Bantuan Hidup Dasar dimaksudkan untuk memberikan pengetahuan pada perawat sehingga terjadi perubahan perilaku, pengetahuan atau kognitif merupakan domain penting untuk terbentuknya tindakan seseorang (Notoatmojo, 2003).

Pengetahuan yang kurang pada penelitian ini disebabkan hampir setegah responden salah menjawab enam item pertanyaan, yaitu: tujuan bantuan hidup dasar; langkah-langkan mengoperasikan AED; peralihan peran saat memberikan RJP dengan dua penolong; posisi pasien setelah denyut nadi dan pernafasan kembali; cara kompresi dada pada bayi dengan dua penolong; tindakan pemberian defirilator. Selain itu lebih dari setengah responden salah menjawab enam item pertanyaan, yaitu pengertian bantuan hidup dasar, pemeriksaan nadi pada anak usia satu tahun sampai remaja, lima langkah dalam rantai survival dewasa, pemberian ventilasi pada pasien dewasa dengan dua penolong, penanganan pasien henti jantung jika tidak terdapat AED, kedalaman kompresi dada untuk pasien dewasa.

\section{SIMPULAN DAN SARAN}

Berdasarkan hasil penelitian yang telah dilakukan bahwa sebagian besar responden memiliki pengetahuan tentang bantuan hidup dasar pada kategori kurang. Hasil penelitian tiap indikator secara keseluruhan berada pada kategori kurang, yaitu pada kelompok pengetahuan konsep dasar, pengkajian respons dalam BHD, resusitasi paru dalam BHD, resusitasi jantung dalam BHD, dan $A E D$ dalam BHD. Perlu dilakukan evaluasi secara berkala, pelatihan mengenai BHD. Dari aspek kebijakan, dapat dilakukan kajian untuk pembaharuan dan sosialisasi SOP pelaksanaan BHD di rumah sakit.

\section{REFERENSI}

Alavi, A., Bahrami, M., Zargham-Boroujeni, A., \& Alireza, Y. (2012). Pediatric nurses' perception of factors associated with caring self-efficacy: A qualitative content analysis. Iranian Journal of Nursing and Midwifery Research, 232238.

Alhidayat, N,A., Rahmat, A., Simunati. (2013). Hubungan Tingkat Pengetahuan Perawat Instaansi Gawat Darurat tentang Pengkajian terhadap Pelaksanaan Tindakan Life Support di Rumah Sakit Pelamonia Makassar. Vol. 2, No.4

Alkatiri, JBS. (2007). Resusitasi Jantung Paru. Dalam: Sudoyo, Aru S. Dkk. (editor). Buku Ajar Ilmu Penyakit Dalam. Edisi IV.

American Heart Association (AHA). (2015). Highlight of the 2015 American Heart Association Guidelines Update for CPR and EGC. Dallas, Texas. 
(2010). Adult Basic Life Support: Guidlines for cardiopulmonary Resuscitation and Emergeny Cardiovascular Care.

Anderson, G., Gaetz, M., \& Masse, J. (2011). First aid skill retention of first responders within the workplace. Journal of Trauma, Resuscitation ang Emergrncy Medicine.

Anderson, L. W., \& Krathwohl, D. R. (2001). A Taxonomy for learning, teaching, and assesing: A revision of Bloom's Taxonomy of Educational Objectives.

Arikunto, S. (2006). Prosedur Penelitian Suatu Pendekatan Praktik, Ed Revisi VI. Jakarta: PT. Rineka Cipta.

Badan Penelitian dan Pengembangan Kesehatan (BPPK) RI. 2008. Riset Kesehatan Dasar (Riskesdas) 2007. Laporan Nasional 2007. Jakarta: Badan Penelitian dan Pengembangan Kesehatan (BPPK) RI.

Biggs, J., \& Tang, C. (2007). Teaching for Quality Learning at University. New York: The Society for Research into Higher Education \& Open University Press.

Bryan, McNally., Rachel, Robb., Monica, Mehta., Kimberly, Vellano., Amy, L. Valderrama., Paula W. Yoon., Comilla, Sasson., Allison, Crouch., Amanda Bray, Perez., Merritt, Robert., \& Kellermann, Arthur Morbidity and Mortality Weekly Report: Surveillance Summaries Vol. 60, No. 8 (July 29, 2011), pp. 1-19 : Centers for Disease Control \& Prevention (CDC)

Budiman, \& Riyanto, A. (2013). Kapita Selekta Kuesioner Pengetahuan dan Sikap dalam Penelitian Kesehatan. Jakarta Selatan: Penerbit Salemba Medika.

Dariyo, Agoes. (2003), Psikologi Perkembangan Dewasa Muda, Jakarta: PT Gramedia Widiasarana.

Depkes. (2006). Kurikulum Penolong Pertama Kedaruratan (Fiert Respoder Emergency Training). Jakarta: Direktorat Jendral Bina Kesehatan Masyarakat.
Fischer, K. W., Yan, Z., \& Stewart, J. (2003). Adult cognitive development: Dynamics in the. Canada: Sage.

Frame, Sottn B. (2003). PHTLS: basic and advenced prehospital trauma life support. (5th ed). Missouri; Mosby.

Herlitz, J., Holmberg, S., Engdahl, J., Svensson, L., \& Young, M. (2006). Can we define patients with no chance of survival after out- of-hospital cardiac arrest?",

1114-1119. http://doi.org/10.1136/hrt.2003.029348

Hurlock, E. B. (2003). Psikologi Perkembangan; Suatu Pendekatan Sepanjang Rentang Kehidupan. Jakarta: Penerbit Erlangga

Keenan, M. Lamacraft,G., \& Joubert,G. (2009). A Survey Of Nurse Basi Life Support Knowledge and training at a tertiary hospital. African journal of Health proffesions Educaton, 1(1), 4-7.

Khalilati, Noor., Supinah., \& Arifin, Zainal. (2017). Hubungan Tingkat Pengetahuan Perawat dengan Ketepatan Kompresi Dada dan Ventilasi menurut AHA Guidelines 2015 di Ruang Perawatan Intensif RSUD $d r$. H. Moch. Ansari Saleh Banjarmasin. Dinamika Kesehatan, Vol. 8 No.1

Krathwohl, D. R., Anderson, L. W., Airasian, P. W., Cruikshank, K. A., Mayer, R. E., Pintrich, P. R., ... Wittrock, M. C. (2002). A taxonomy for learning, teaching, and assessing: A revision of Bloom's taxonomy of educational objectives,(Abridged Edition). New York Longman, Complete e(4), 302. https://doi.org/10.1207/s15430421tip41 $\underline{04 \_2}$

Notoatmodjo, S. (2003). Metodologi Penelitian Kesehatan. Jakarta: Rineka Cipta

Nursalam.(2009). Konsep dan Penerapan Metodologi Penelitian Ilmu Keperawatan. Jakarta:Salemba Medika

Mpotos, N., Decaluwe, K., Belleghem, V. V., Cleymans, N., Raemaekers, J., Derese, A., Monsieurs, K. G. (2015). Automated testing combined with 
automated retraining to improve CPR skill level in emergency nurses. Elsevier: Nurse Education in Practice, 212-217.

doi:10.1016/j.nepr.2014.11.012

Papila, D. E., Sterns, H. L., Feldman, R.D., Camp, C. J. (2007). Adult Development and Aging, $3^{\text {rd }}$. New York : MaGraw Hills

Partiprajak, S., \& Thongpo, P. (2016). Retention of basic life support knowledge, self-effi cacy and chest compression performance in Thai undergraduate nursing students. Elsevier, 235-241. doi:10.1016/j.nepr.2015.08.012

Passali, C., Pantazopoulos, I., Dontas, I., Patsaki, A., Barouxis, D., Troupis, G., \& Xanthos, T. (2011). Evaluation of nurses' and doctors' knowledge of basic $\&$ advanced life support resuscitation guidelines. Elsevier, 365-369. doi:10.1016/j.nepr.2011.03.010

Polit, \& Hungler. (2006). NursingrResearch: Principles and methods. (6th ed). Philadelphia: Lippincott Williams and Wikins.

Pusponegoro A, et al. (2010). Buku Panduan Basic Trauma Life Support. Ed. Ke 3. Penerit Yayasan Ambulans Gawat Darurat 18. Jakarta.

Rasjad C. Trauma. Dalam: Rasjad MI, Rasyid MY, penyunting. Pengantar Ilmu Bedah Ortopedi. Jakarta: Yarsif Watampone, 2007: 318-475, n.d.

Suharty, Dahlan. (2014). Pengaruh Pendidikan Kesehatan Tentang Bantuan Hidup Dasar (BHD) Terhadap Tingkat Pengetahuan Tenaga Kesehatan di Puskesmas Wori Keamatan Wori Kabupaten Minahasa
Utara. Ejournal Keperawatan (e-Kp) Voleme 2, Nomor 1. Minahasa Utara

Suharsono, T. Ningsih, D. (2012). Penatalaksanaan Henti Jantung Di Luar Rumah Sakit, Malang : UMM Press.

Svensson, Anders., \& Fridlund, Bengt. (2008). Experiences of and actions towards worries among ambulance nurses in their professional life: $A$ critical incident study. Elsevier: international Emergency Nursing 16, 35-

Toubasi, Samar., R. Alosta, Mohammed., W. Darawad., Demeh, Waddah. (2015). Impact of simulation training on Jordanian nurses' performance of basic life support skills: A pilot study. Elsevier, doi:dx.doi.org/10.1016/j.nedt.2015.03.0 17

Thygerson, Alton.(2009). First Aid: Pertolongan Pertama Edisi kelima. Jakarta: penerbit Erlangga

Vaillancourt, Christian, \& Stiell, Ian, G. (2004). Cardiac Arrest Care and Emergency Medical Services in Canada. The Canadian Journal of Cardiology, 20(11):181-197

Wawan A \& Dewi M. (2011). Teori dan Pengukuran Pengetahuan, Sikap dan Perilaku. Yogyakarta: Muha Medika

WHO. (2011). Mortality, road traffic deaths. Maret 29, 2012. http://apps. who.int/ghodata/?vid=5120

Widiko, E. (2012). A study on knowledge, attitude, and pravtice of first aid among undergraduate medical students in tanzania 2012. Elective study report, $1-22$. 